\title{
NMR and Chemometric Characterization of Vacuum Residues and Vacuum Gas Oils from Crude Oils of Different Origin
}

\author{
Jelena Parlov Vuković, a,* Predrag Novak, ${ }^{\mathrm{b}}$ Janez Plavec, ${ }^{\mathrm{c}}$ \\ Miha Friedrich, ${ }^{\mathrm{c}}$ Ljiljana Marinić Pajc, ${ }^{\mathrm{a}}$ and Tomica Hrenar ${ }^{\mathrm{b}, *}$ \\ a INA-Industrija nafte d.d., Refining \& marketing business division, Product development department, \\ Lovinčićeva 4, 10002 Zagreb, Croatia \\ ${ }^{\mathrm{b}}$ University of Zagreb, Faculty of Science, Department of Chemistry, Horvatovac 102a, \\ HR-10000, Zagreb, Croatia \\ ${ }^{\mathrm{c}}$ NMR Center, National Institute of Chemistry, SI-1000 Ljubljana, Slovenia
}

RECEIVED MARCH 2, 2015; REVISED MARCH 27, 2015; ACCEPTED MARCH 27, 2015

\begin{abstract}
NMR spectroscopy in combination with statistical methods was used to study vacuum residues and vacuum gas oils from 32 crude oils of different origin. Two chemometric metodes were applied. Firstly, principal component analysis on complete spectra was used to perform classification of samples and clear distinction between vacuum residues and vacuum light and heavy gas oils were obtained. To quantitatively predict the composition of asphaltenes, principal component regression models using areas of resonance signals spaned by 11 frequency bins of the ${ }^{1} \mathrm{H}$ NMR spectra were build. The first 5 principal components accounted for more than $94 \%$ of variations in the input data set and coefficient of determination for correlation between measured and predicted values was $R^{2}=0.7421$. Although this value is not significant, it shows the underlying linear dependence in the data. Pseudo two-dimensional DOSY NMR experiments were used to assess the composition and structural properties of asphaltenes in a selected crude oil and its vacuum residue on the basis of their different hydrodynamic behavior and translational diffusion coefficients. DOSY spectra showed the presence of several asphaltene aggregates differing in size and interactions they formed. The obtained results have shown that NMR techniques in combination with chemometrics are very useful to analyze vacuum residues and vacuum gas oils. Furthermore, we expect that our ongoing investigation of asphaltenes from crude oils of different origin will elucidate in more details composition, structure and properties of these complex molecular systems.
\end{abstract}

Keywords: NMR, PCA, PCR, crude oils, vacuum residues and gas oils, asphaltenes

\section{INTRODUCTION}

A common characteristic of crude oil is a very complex chemical composition. Crude oils consist of thousands of individual components (organic molecules), ranging in size, mainly composed of carbon and hydrogen atoms. An understanding of crude oil composition and properties is of crucial importance in the oil industry in order to apply appropriate processing facilities. Due to a decrease in light oil reserves, the main goal today is to refine large quantities of heavy crude oils, to transform them into good quality commercial products with low operational costs and to obey the environmental specification. ${ }^{1,2}$

The composition of crude oil is generally assessed by the standard methods such as ASTM methods
(American Society for Testing and Materials) which are time consuming, elaborate and expensive, requiring substantial amounts of the samples and appropriate solvents. Hence, faster, cheaper and simpler methods are highly needed. NMR spectroscopy has already been proven very useful for the analysis of oil, oil derivatives and products. ${ }^{3-10}$ For complex mixture, such as mineral fuels, high resolution ${ }^{1} \mathrm{H}$ and ${ }^{13} \mathrm{C}$ NMR spectroscopy provided valuable information on average structural parameters and quantitative distribution of hydrogens and carbons. ${ }^{11,12}$

Vacuum residuesand vacuum gas oils are one of the main byproducts of oil refining. These are very difficult to handle owing to their high viscosity. Hence, we used here a combination of NMR spectroscopy and statistical methods to evaluate vacuum residues

\footnotetext{
* Authors to whom correspondence should be addressed. (E-mail: jelena.parlov-vukovic@ina.hr, hrenar@chem.pmf.hr)
} 
(samples 1-20) and vacuum light and heavy gas oils (samples 21-32) from 32 crude oils of different origin. A special attention was paid to the analysis of asphaltenes. Asphaltenesare complex organic macromolecular mixtures containing condensed aromatic and saturated rings, aliphatic moieties and different heteroatoms. ${ }^{13}$ Asphaltenes may aggregate and precipitate during petroleum processing and form aggregates causing serious problems including reduction in oil flow, blocking of production pipes and some drawbacks during the processing of heavy ends such as coke formation, catalyst deactivation and poisioning. ${ }^{14}$ Asphaltenes can be present in both crude oil and its vacuum residue which is one of the main byproducts of oil refining. ${ }^{15,16}$ Despite many efforts and variety of analytical methods used, accurate data on molecular weight, size, shape and structure of asphaltenes are still scarce in the literature and their properties not completely elucidated. ${ }^{1,2,14}$ We applied here a pseudo two dimensional DOSY NMR technique to preliminary characterize composition and structure of these complex molecular systems.

\section{EXPERIMENTAL}

\section{Samples}

All crude oil samples were of different origin and processed during 2012-2014 in Croatian refinery. The distillation and fractionation of the crude oil samples were made on fully automatic distillation apparatuses EuroDist System True Boiling Point and EuroDist System Postill in accordance with standard methods ASTM D 2892-13 and ASTM D 5236-13. ${ }^{17,18}$ The crude oils were fractionated in several fractions including those above $550{ }^{\circ} \mathrm{C}$.

Asphaltenes were obtained from crude oil sample and heavy vacuum residue fractions by using ASTM D 6560-12 method. ${ }^{19}$ It is the standard test method for the determination of the heptane insoluble asphaltene content. A test portion of the sample was mixed with heptane, the mixture was heated under reflux and the precipitated asphaltenes, waxy substances, and inorganic material were collected on a filter paper. The waxy substances were removed by washing with hot heptane in an extractor. After removal of the waxy substances, the asphaltenes were separated from the inorganic material by dissolution in hot toluene and the extraction solvent was evaporated.

\section{NMR Spectroscopy}

All one dimensional ${ }^{1} \mathrm{H}$ and ${ }^{13} \mathrm{C}$ NMR spectra were recorded on a Bruker Avance $300 \mathrm{NMR}$ spectrometer operating at $300 \mathrm{MHz}$ for ${ }^{1} \mathrm{H}$ and $75 \mathrm{MHz}$ for ${ }^{13} \mathrm{C}$ using a $\mathrm{C} / \mathrm{H}$ dual $5 \mathrm{~mm}$ probe. The experiments were performed at room temperature. Chemical shifts are reported relative to tetramethylsilane (TMS) used as an internal standard.

The ${ }^{1} \mathrm{H}$ NMR experiments were carried out using $5 \%(w / w)$ solution in $\mathrm{CDCl}_{3}(99.8 \%$ Aldrich $)$ with 32 scans, 2 s recycle delay, $7.6 \mu$ s $\pi / 2$ pulse length and $16 \mathrm{~K}$ time domain data.

A $50 \%(w / w)$ sample solution was prepared in deuterated chloroform $(99.8 \%$ D) containing approx. $0.1 \mathrm{~mol} \mathrm{dm}^{-3}$ chrom(III) acetylacetonat as relaxation agent to reduce the spin-lattice relaxation time. ${ }^{12}$

The measuring conditions for quantitative inverse gated ${ }^{13} \mathrm{C}$ NMR experiments were: $18 \mathrm{kHz}$ sweep width; $8.70 \mu$ s pulse width; 10 s relaxation delay; 1024 scans.

${ }^{1} \mathrm{H}$ NMR DOSY spectra were acquired on Agilent Technologies DD2 $600 \mathrm{MHz}$ NMR spectrometer equipped with a cold probe. Measurements were performed under the following conditions: 128 scans, $1.5 \mathrm{~s}$ relaxation delay, $10.0 \mathrm{kHz}$ sweep width, and $32 \mathrm{~K}$ time domain. In 25 experiments the gradient strength was incremented from 0.5 to $26.1 \mathrm{G} \mathrm{cm}^{-1}$ in steps of $c a$. $1.1 \mathrm{G} \mathrm{cm}^{-1}$, while delays 'small delta' $(6 \mathrm{~ms})$ and 'big delta' (131.8 ms) were kept constant. Samples were dissolved in $\mathrm{CDCl}_{3}$. Sample temperature was set at $298 \mathrm{~K}$.

\section{Multivariate Data Analysis}

Numerical analysis were performed using the second order tensor analysis tool PCA where data matrix (or two-way array) $\boldsymbol{X}$ of rank $\boldsymbol{r}$ is decomposed as a sum of $\boldsymbol{r}$ matrices $\boldsymbol{t}_{i} \boldsymbol{p}_{i}^{\tau}$ of rank 1

$$
\boldsymbol{X}=\sum_{i=1}^{r} \boldsymbol{t}_{i} \boldsymbol{p}_{i}^{\tau}
$$

where $\boldsymbol{t}_{i}$ stands for score and $\boldsymbol{p}_{i}{ }^{\tau}$ for loading vectors. PCA finds the best linear projections for a high dimensional set of data in the least squares sense. Scores represent projections of the original points on the principal component (PC) direction and can be used for classification, whereas loadings represent eigenvectors of data covariance (or correlation) matrix and can be used for the identification of variability among the data. Development of PCA goes back to Beltrami ${ }^{20}$ and Pearson ${ }^{21}$ while the name was introduced by Hotteling. ${ }^{22}$ More details can be found in the recent literature. ${ }^{23,24}$

Data obtained by NMR spectral measurements of different samples were exported to the ASCII format and arranged in a matrix (numbers written in a free format). Numerical integration was performed and relative intensities were calculated in 11 spectral regions. Data were mean-centered and PCA on the covariance matrix was carried out using code moone $e^{25}$ based on the NIPALS algorithm. ${ }^{26}$ Most of the calculated eigenvectors converged within a small number of iterations 
which took only few minutes of computational time on an average workstation.

Principal component regression (PCR) models were developed for predicting asphaltenes using areas of resonance signals spanned by 11 frequency bins of the ${ }^{1} \mathrm{H}$ NMR spectra. In this method orthogonal principal components were generated and regression models were developed between principal component scores and the properties of interest. Estimated mean square error of prediction and the determination coefficient $\left(R^{2}\right)$ of the predictive model were used for evaluating the PCR model.

\section{RESULTS AND DISCUSSION}

\section{${ }^{1}$ H NMR Analysis of Vacuum Residues and Vacuum Gas Oils}

As already mentioned crude oil is a complex mixture of thousands of chemical compounds. The typical ${ }^{1} \mathrm{H}$ and ${ }^{13} \mathrm{C}$ NMR spectra of the crude oil sample are displayed in the Figure 1. A chemical composition of vacuum residues (samples 1-20) and vacuum gas oils (samples 21-32) from crude oil samples have been determined from the analysis of ${ }^{1} \mathrm{H}$ NMR spectra using the procedure described in our previous paper ${ }^{12}$ and expressed as the percentage of different types of hydrocarbons (Table $\mathrm{S}$, supplementary data). Table 1 lists the characteristic functional groups in vacuum residues and vacuum gas oils, the spectral regions in which their protons resonate and letters designating integrated regions of interest. Integrated proton peak intensities are proportional to the number of hydrogen nuclei in each functional group. The resulting integrals were normalized. Asphaltene contents were previously estimated using the standard ASTM procedure (Table S).

It is seen from the Table $S$ that the percentage of asphaltens is higher in vacuum residue samples $\mathbf{1 - 2 0}$ than in vacuum gas oils 21-32 which is expected due to

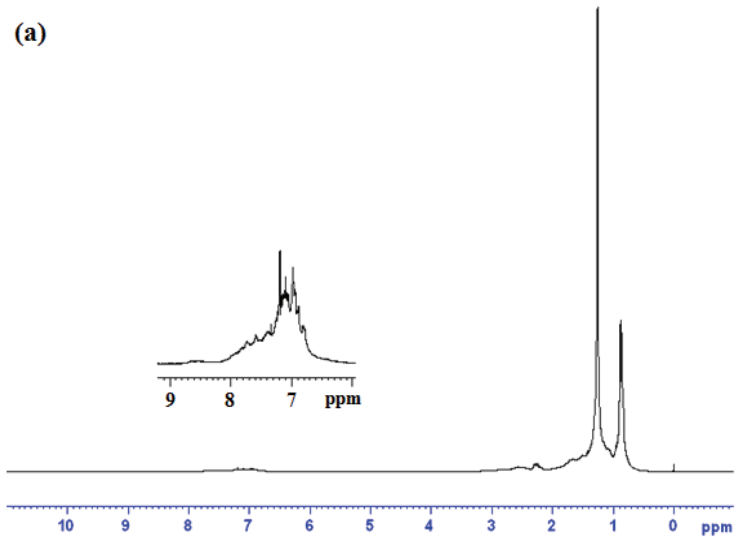

Table 1. Frequency bins of the ${ }^{1} \mathrm{H}$ NMR spectra used for PCR predicting models

\begin{tabular}{|c|c|c|}
\hline $\begin{array}{c}\text { Frequency } \\
\text { bin }\end{array}$ & $\begin{array}{c}\text { Spectral range / } \\
\text { ppm }\end{array}$ & Hydrogen type \\
\hline A & $8.9-9.3$ & some tetra-aromatic \\
\hline B & $8.3-8.9$ & $\begin{array}{l}\text { some tri- and tetra- } \\
\text { aromatic }\end{array}$ \\
\hline $\mathrm{C}$ & $7.2-8.3$ & $\begin{array}{l}\text { di-aromatic and some tri- } \\
\text { and tetra-aromatic }\end{array}$ \\
\hline $\mathrm{D}$ & $6.0-7.2$ & mono-aromatic \\
\hline $\mathrm{E}$ & $3.5-4.5$ & bridging $\mathrm{CH}_{2}$ \\
\hline $\mathrm{F}$ & $2.4-3.5$ & $\begin{array}{c}\alpha-\mathrm{CH}, \mathrm{CH}_{2} \text { in aromatic } \\
\text { carbons }\end{array}$ \\
\hline G & $2.1-2.4$ & $\alpha-\mathrm{CH}_{3}$ in aromatic carbon \\
\hline $\mathrm{H}$ & $1.9-2.1$ & $\alpha-\mathrm{CH}_{3}$ in olefins \\
\hline I & $1.7-1.9$ & $\begin{array}{c}\text { most } \mathrm{CH}, \mathrm{CH}_{2} \text { in } \\
\beta \text { positions }\end{array}$ \\
\hline $\mathrm{J}$ & $1.0-1.7$ & $\beta-\mathrm{CH}_{2}$, and some $\beta-\mathrm{CH}$ \\
\hline K & $0.5-1.0$ & $\begin{array}{c}\gamma-\mathrm{CH}_{3} \text {, some naphtenic } \\
\mathrm{CH} \text { and } \mathrm{CH}_{2}\end{array}$ \\
\hline
\end{tabular}

the fact that asphaltenes are high molecular weight mixtures obtained at temperatures above $500{ }^{\circ} \mathrm{C}$.

\section{Multivariate Analysis}

Principal Component Analysis

To statistically evaluate crude oil samples we first use PCA method. The results of PCA are shown in Table 2 where the total variances described by principal components for a set of relative intensities in NMR spectra for 32 samples are presented.

The first principal components (PC1) explained only $61.84 \%$ of spectral variance. However, when the $\mathrm{PC} 1$ is coupled with PC2 and PC3 that accounts for $97.01 \%$ of the total variance thus providing the excellent description of the original data. Classification using first three principal components is presented in Figure 2 .

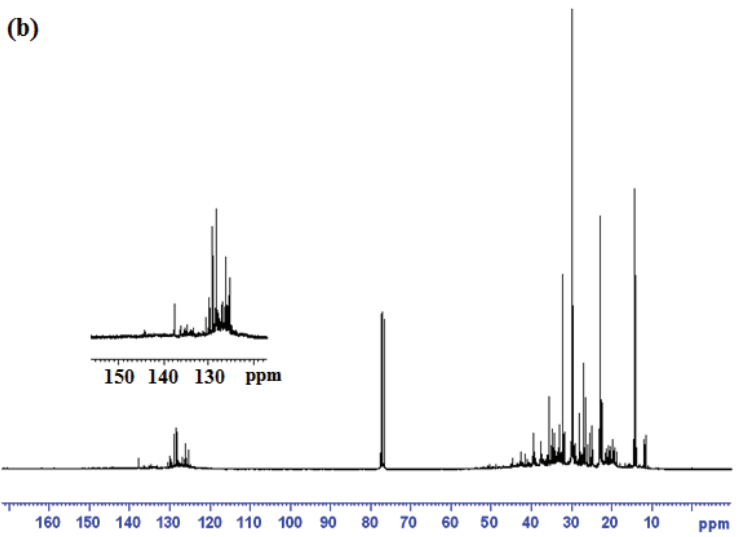

Figure 1. (a) ${ }^{1} \mathrm{H}$ spectrum and (b) ${ }^{13} \mathrm{C}$ NMR spectrum of crude oil sample. Vertical scales in insets of ${ }^{1} \mathrm{H}$ and ${ }^{13} \mathrm{C}$ spectra have been increased by 12.5 and 2.5 times, respectively. 
Table 2. Total variance represented by principal components for a set of relative intensities in NMR spectra for 32 samples

\begin{tabular}{ccc}
\hline \multirow{2}{*}{$\begin{array}{c}\text { Principal } \\
\text { component }\end{array}$} & \multicolumn{2}{c}{ Variance / \% } \\
\cline { 2 - 3 } & Individual & Cumulative \\
\hline PC1 & 61.84 & 61.84 \\
PC2 & 31.55 & 93.39 \\
PC3 & 3.61 & 97.01 \\
PC4 & 1.73 & 98.73 \\
PC5 & 0.65 & 99.39 \\
\hline
\end{tabular}

Clear distinction between vacuum residues (samples 1-20) and vacuum light and heavy gas oils (samples 21-32) can be observed on the score plots. Differences among the samples arise from the spectral area presented on loading plots (Figure 3).

The most significant changes are presented in Figure 3a. The spectral area from 1.7-1.0 ppm is showing the increase in aliphatic hydrogens content. The signal is pointing into the negative region due to the properties of NIPALS algorithm, but by examining raw data it was clear that the signals in the negative direction of PC1 shows increase in content, and the signals in the positive direction show decrease in content. This

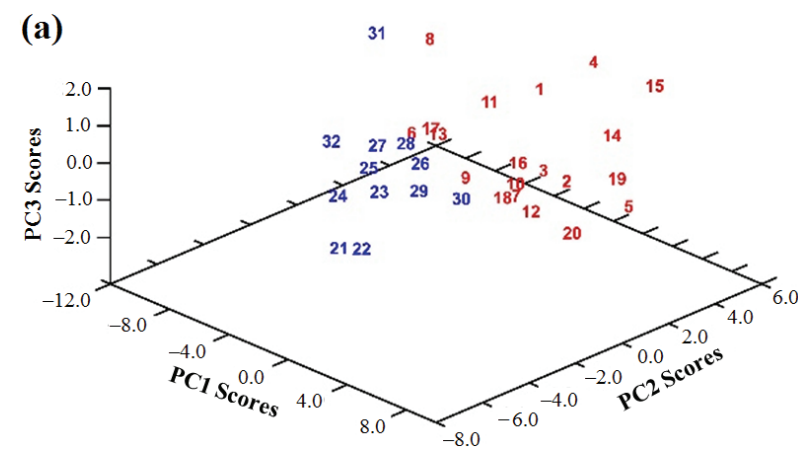

(b)

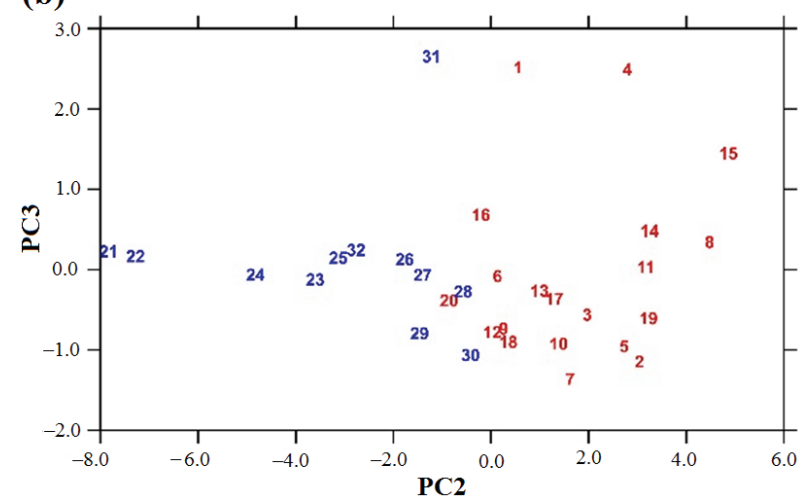

Figure 2. Classification of samples using the scores of (a) the first three principal components obtained by PCA and (b) projection on the second and the third principal component. Samples 1-20 are vacuum residues (red labels) and samples 21-32 are vacuum light and heavy gas oils (blue labels). (a)

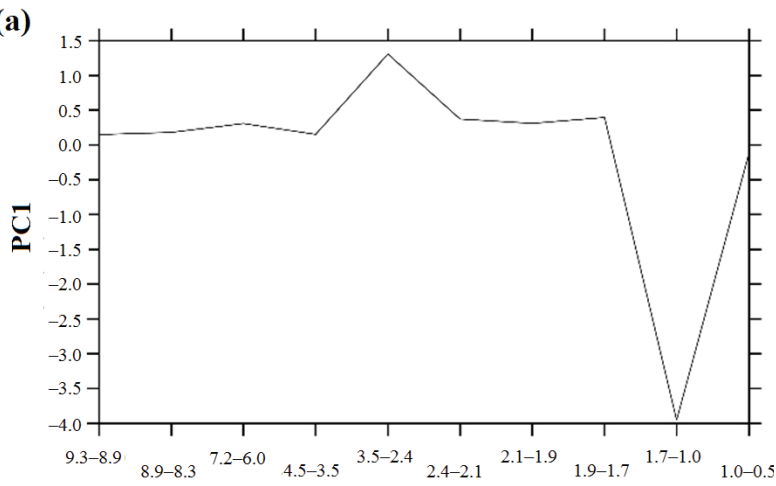

Spectral range / ppm

(b)

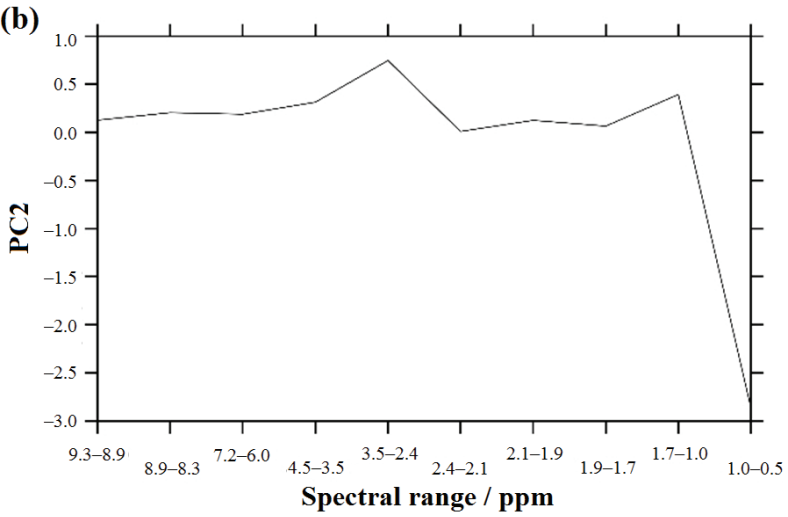

Figure 3. (a) PC1 and (b) PC2 loadings obtained by PCA conducted on the set of 32 samples.

increase in aliphatic hydrogen content is followed by the decrease in aromatic hydrogen content. These results indicate general decrease of aromatic compounds in samples 21-32.

\section{Principal Component Regression}

PCR models were then applied for predicting asphaltene content using areas of resonance signals spaned by 11 frequency bins of the ${ }^{1} \mathrm{H}$ NMR spectra (Table 1). The first 5 components of the PCR accounted for $>94 \%$ of

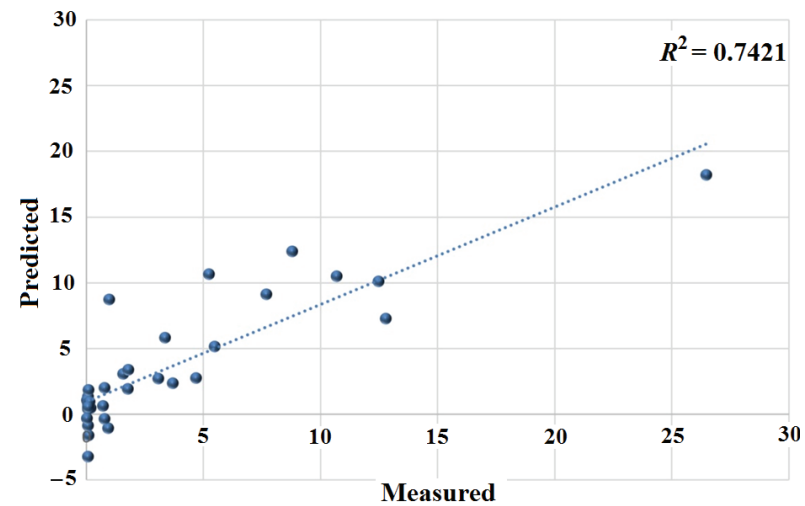

Figure 4. Correlation between measured and predicted values from PCR performed on 11 frequency bins of the ${ }^{1} \mathrm{H}$ NMR spectra. 
Table 3. The percentage (\%) of different hydrogens obtained from ${ }^{1} \mathrm{H}$ spectra in the samples $18-\mathbf{1 8 c}$

\begin{tabular}{|c|c|c|c|c|}
\hline $\begin{array}{l}\text { Functional group } \\
\delta / \mathrm{ppm}\end{array}$ & $\begin{array}{c}\text { Sample 18a } \\
\%\end{array}$ & $\begin{array}{c}\text { Sample } 18 \\
\%\end{array}$ & $\begin{array}{c}\text { Sample 18b } \\
\%\end{array}$ & $\begin{array}{l}\text { Sample 18c } \\
\%\end{array}$ \\
\hline $\begin{array}{l}\text { Aromatic hydrogens }\left(\mathrm{H}_{\mathrm{ar}}\right) \\
\quad 7.20-9.00\end{array}$ & 3.76 & 3.82 & 13.08 & 9.80 \\
\hline $\begin{array}{l}\text { Hydrogens } \alpha \text { to aromatic ring }\left(\mathrm{H}_{\alpha}\right) \\
\qquad 2.10-3.80\end{array}$ & 7.01 & 8.43 & 17.17 & 20.99 \\
\hline $\begin{array}{c}\beta, \gamma-\mathrm{CH}_{2} \text { and } \mathrm{CH} \text { in to aromatic ring } \\
\text { and paraffinic } \mathrm{CH}, \mathrm{CH}_{2}\left(\mathrm{H}_{\beta}\right) \\
1.00-2.10\end{array}$ & 61.87 & 64.32 & 50.07 & 51.41 \\
\hline $\begin{array}{l}\beta, \gamma-\mathrm{CH}_{3} \text { to aromatic ring and paraffinic } \mathrm{CH}_{3}\left(\mathrm{H}_{\gamma}\right) \\
0.50-1.00\end{array}$ & 27.36 & 23.46 & 19.15 & 17.78 \\
\hline
\end{tabular}

variations in the input data set. The obtained quantitative model for the content of asphaltenes over the frequency bin variables is represented with the following equation

$$
\begin{aligned}
W= & -8.71-31.19 \cdot A+8.38 \cdot B+7.51 \cdot C+ \\
& 10.10 \cdot D-4.01 \cdot E+2.79 \cdot F+5.40 \cdot G- \\
& 10.47 \cdot H-8.41 \cdot I-0.44 \cdot J+0.90 \cdot K
\end{aligned}
$$

and the correlation between measured and predicted values is presented in Figure 4.

Coefficient of determination for correlation between measured and predicted values was $R^{2}=0.7421$ and the estimated standard error of prediction was 2.484 .

\section{Structural Analysis of Asphaltenes by ${ }^{1} \mathrm{H},{ }^{13} \mathrm{C}$ and DOSY NMR}

As already mentioned, for the complex mixture such as crude oil ${ }^{1} \mathrm{H}$ and ${ }^{13} \mathrm{C}$ NMR spectroscopy can provide valuable data about the presence and amountsof different hydrocarbons in a quantitative way. ${ }^{27}$ Furthermore, DOSY NMR technique, ${ }^{2,28}$ can differentiate between components present in a mixture owing to their distinct translational diffusion coefficients and give information on their size and structure. Hence, we explore here the possibilities of these NMR techniques to analyze asphaltenes present in the selected crude oil sample (18a). Firstly, we determined the content of aliphatic carbons and hydrogens which amounted to be $86 \%$ and $96 \%$, respectively, while the rest were aromatics. It is clearly seen in the Tables 3 and 4 that asphaltene samples 18b and 18c have much higher portions of aromatic compounds while the content of paraffins decreases. In line with this, $\mathrm{C} / \mathrm{H}$ ratio increase confirming higher percentage of aromatic rings in $\mathbf{1 8 b}$ and $\mathbf{1 8 c}$. From data presented in the Table 4 aromaticity can be determined as the difference between the total carbons and the sum of all aliphatic carbon as shown with equation (3):

$$
\text { Aromaticity }=1-\sum \mathrm{C}_{\text {aliphatic }}
$$

Hence, aromaticity for the samples $\mathbf{1 8 a}, \mathbf{1 8}, \mathbf{1 8 b}$ and $18 \mathrm{c}$ was calculated to be $0.14,0.18,0.50$ and 0.57 , respectively. These values show that asphaltene samples $18 \mathrm{~b}$ and $18 \mathrm{c}$ consist of more aromatic structures than the other two samples, being in accordance with previously discussed results.

Slightly larger amount of aromatic carbons and lower amount of the total aliphatic carbons might suggest that in the sample $\mathbf{1 8 b}$ more condensed or fused aromatic rings are present compared to those in the sample 18c, having larger amounts of compounds with aliphatic chains.

To further analyze asphaltenes, we have recorded DOSY spectra of the crude oil and the vacuum residue,

Table 4. The percentage (\%) of different carbons in the samples 18-18c

\begin{tabular}{ccccc}
\hline Functional group & Sample 18a & Sample 18 & Sample 18b & \multicolumn{2}{c}{ Sample 18c } \\
$\% /$ ppm & $\%$ & 82.27 & 50.00 & 43.18 \\
\hline Aliphatic carbons $\left(\mathrm{C}_{\mathrm{al}}\right)$ & 86.30 & 17.73 & 50.00 & 56.82 \\
Aromatic carbons $\left(\mathrm{C}_{\mathrm{ar}}\right)$ & 13.70 & 40.42 & 18.15 & 15.91 \\
Naphtenic carbons $\left(\mathrm{C}_{\mathrm{n}}\right)$ & 37.53 & 41.81 & 31.10 & 27.27 \\
Paraffinic carbons $\left(\mathrm{C}_{\mathrm{p}}\right)$ & 48.77 & 29.07 & 22.50 & 20.45 \\
Normal paraffins $\left(\mathrm{C}_{\mathrm{np}}\right)$ & 37.94 & 12.78 & 9.00 & 6.82 \\
Iso paraffins $\left(\mathrm{C}_{\mathrm{ip}}\right)$ & 10.83 & 54.86 & 66.67 & 69.84 \\
C/H ratio & 53.68 & & &
\end{tabular}




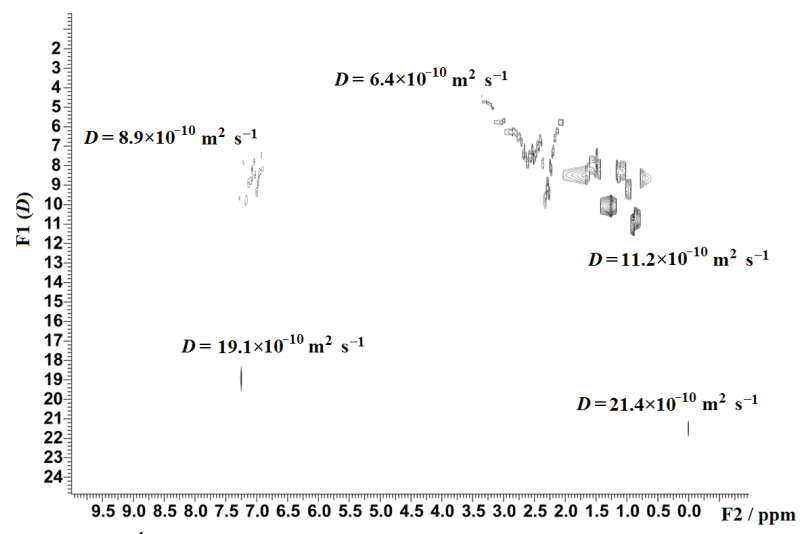

Figure 5. ${ }^{1} \mathrm{H}$ NMR DOSY spectrum of the sample $\mathbf{1 8 .}$

18a and 18 (Figures 5 and 6) and asphaltenes obtained from the crude oil and the vacuum residue $\mathbf{1 8 b}$ and $\mathbf{1 8 c}$ (Figures 7 and 8).

By applying the standard ASTM method the percentage of asphaltenes in the crude oil and vacuum residue samples were calculated to be $1.2 \%$ and $7.7 \%$, respectively. It has been demonstrated in the literature ${ }^{1}$ that asphaltenes may aggregate to form nano-, microand macro-aggregates in increasing order of size. Hence, one would expect that these aggregates can be differentiated in the DOSY spectra according to their translational diffusion coefficients. Thus, the lowest diffusion coefficient has been observed for macroaggregates and the highest for nano-aggregates, as can be seen in the Figures 7 and 8. Macro-aggregates species have the lowest diffusion coefficients in the range $1.7-1.8 \cdot 10^{-10} \mathrm{~m}^{2} \mathrm{~s}^{-1}$, micro-aggregates in the range $2.7-3.5 \cdot 10^{-10} \mathrm{~m}^{2} \mathrm{~s}^{-1}$, while the highest values have been found for nano-aggregates, 5.7-7.0 $10^{-10} \mathrm{~m}^{2} \mathrm{~s}^{-1}$. Variations in diffusion coefficients for the same group of aggregates might be accounted for by slightly different composition and intermolecular interactions formed as well as different concentrations. This observation is in accordance with data presented in Tables 3 and 4. Concentration-dependent measurements are expected to

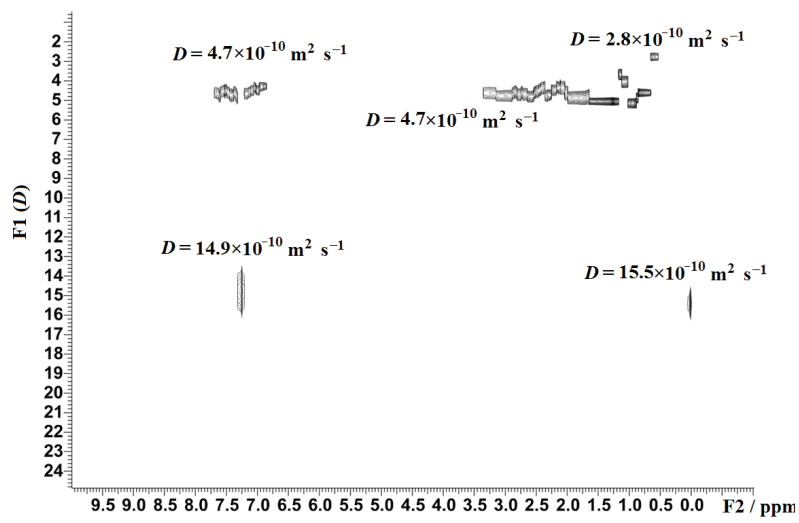

Figure 6. ${ }^{1} \mathrm{H}$ NMR DOSY spectrum of the sample 18a.

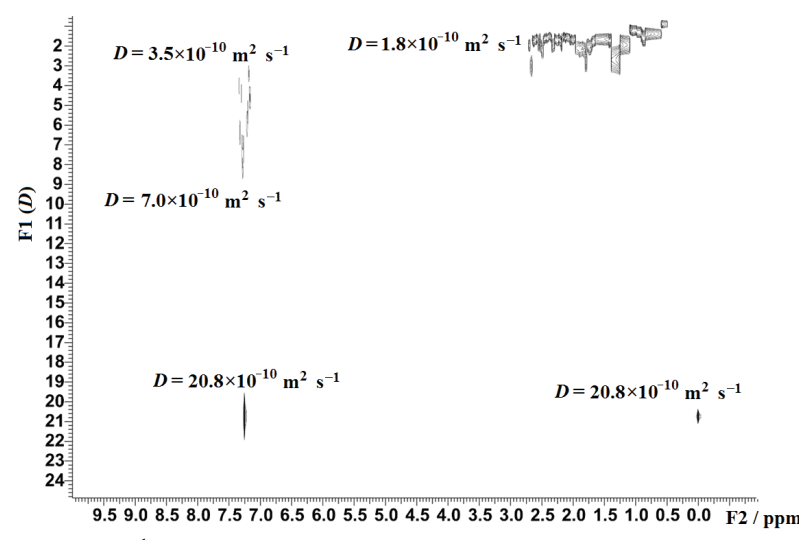

Figure 7. ${ }^{1} \mathrm{H}$ NMR DOSY spectrum of the sample $\mathbf{1 8 b}$.

elucidate in more details asphaltene properties in solution. Furthermore, the separation between micro- and nano-aggregates in the sample $\mathbf{1 8 b}$ with respect to $\mathbf{1 8 c}$ is not complete probably due to the fact that more species are present in $\mathbf{1 8 b}$ forming additional interactions. The variation between diffusion coefficients of microand nano-aggregates in $\mathbf{1 8 b}$ is larger than expected, which implies that intermediate aggregation species might be present, e.g. submicro-aggregates. Our ongoing investigations on larger number of asphaltene samples, which include a combination of NMR techniques $\left({ }^{1} \mathrm{H},{ }^{13} \mathrm{C}\right.$ and DOSY $)$ and statistical methods, will elucidate in more details the nature and structure of these very complex systems.

\section{CONCLUSION}

It has been shown that NMR spectroscopy coupled with statistical methods is a valuable tool for the investigation of crude oil and asphaltene samples. Principal component analysis performed on complete ${ }^{1} \mathrm{H}$ NMR spectra can differentiate samples and reveal spectral areas responsible for classification. From the analysis of ${ }^{1} \mathrm{H}$ and ${ }^{13} \mathrm{C}$ NMR spectra and integration of peak

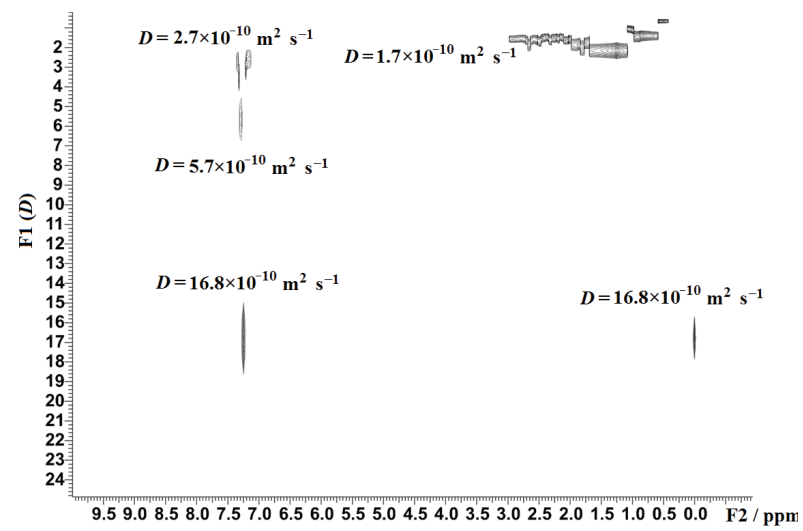

Figure 8. ${ }^{1} \mathrm{H}$ NMR DOSY spectrum of the sample 18c. 
intensities a chemical composition of the studied complex systems and quantitative statistical models can be obtained. Our future investigation will include optimization techniques to extract the most significant parts of the NMR spectra to obtain better quantitative models.

The DOSY NMR experiments have provided further information about the aggregates present in the asphaltene samples. Different clusters of compounds have been indicated, e.g. nano-, submicro-, micro- and macro-aggregates differing in size, shape and type of interactions they formed.

\section{REFERENCES}

1. E. C. da Silva Oliveria, A. C. Neto, V. L. Yunior, E. V. R. de Castro, and S. M. C. de Menezes, Fuel 117 (2014) 146-151.

2. S. L. Silva, A. M. S. Silva, J. C. Ribeiro, F. G. Martins, F. A. D.Silva, and C. M. Silva, Anal. Chim. Acta 707 (2011) 18-37 and references cited therein.

3. Y. K. Sharma, A. Adhvaryu, J. M. Perez, and S. Z. Erhan, Fuel Proces. Teh. 89 (2008) 984-991.

4. G. S. Kapur, M. Findeisen, and S. Berger, Fuel 79 (2000) 1347-1351

5. V. Bansal, G. J. Krishna, A. P. Singh, A. K. Gupta, and A. S. Sarpal, Energy Fuels 22 (2008) 410-415.

6. J. Burri, R. Crockett, R. Hany, and D. Rentsch, Fuel 83 (2004) 187-193.

7. C. R. Kaiser, J. L. Borges, A. R. Santos, D. A. Azevedo, and L. A. D. Avila, Fuel 89 (2010) 99-104

8. J. Mühl and V. Srića, Fuel 66 (1987) 1146-1149.

9. J. Mühl, V. Srića, and M. Jednačak, Fuel 68 (1989) 201-203.

10. J. Mühl, V. Srića, and M. Jednačak, Fuel 72 (1993) 987-989.
11. J. Parlov Vuković, S. Telen, V. Srića, and P. Novak, Croat. Chem. Acta 84 (2011) 537-541.

12. J. Parlov Vuković, V. Srića, and P. Novak, Kem. Ind. 61 (2012) 513-522.

13. T. Fergoug and Y. Bouhadda, Fuel 115 (2014) 521-526.

14. R. C. Silva, P. R. Seidi, S. M. C. Menezes, and M. A. G. Teixeira, Ann. Magn. Reson. 3 (2004) 63-67.

15. S. O. Honse, S. R. Ferreira, C. R. E. Mansur, and E. F. Lucas, Quim. Nova 35 (2012) 1991-1994.

16. F. B. Silva, M. J. O. C. Guimaraes, P. R. Seidi, and M. E. F. Garcia, BJPG 7 (2013) 107-118.

17. Standard Test Method for Distillation of Crude Petroleum (15Theoretical Plate Column), ASTM D 2892-13.

18. Standard Test Method for Distillation of Heavy Hydrocarbon Mixtures (Vacuum Potstill Method), ASTM D 5236-13.

19. Standard Test Method for Determination of Asphaltenes (Heptane Insoluble) in Crude Petroleum and Petroleum Products, ASTM D 6560-12.

20. E. Beltrami, Giornale di Matematiche ad Uso degli Studenti Delle Universita 11 (1873) 98-106.

21. K. Pearson, Phil. Mag. 2 (1901) 559-572.

22. H. Hotelling, J. Educ. Psychol. 24 (1933) 417-441.

23. I. T. Jolliffe, Principal Component Analysis, Springer, Berlin, 1986.

24. A Smilde, R. Bro, and P. Geladi, Multi-way Analysis with Applications in the Chemical Sciences, John Wiley \& Sons Ltd, Chichester, 2004.

25. T. Hrenar, moonee, Code for Manipulation and Analysis of Multi- and Univariate Data, rev. 0.682, 2015.

26. P. Geladi and B. Kowalski, Anal. Chim. Acta 185 (1986) 1-17.

27. D. V. Molina, U. N. Uribe, and J. Murgich, Fuel 89 (2010) 185-192.

28. E. Durand, M. Clemency, A.-A. Quvineaud, J. Verstraete, D. Espinat, and J. M. Lamcelin, Energy Fuel 22 (2008) 2604-2610 


\section{SUPPLEMENTARY MATERIAL}

Table S. Contents of asphaltenes determined by using standard ASTM D 6560-12 method and from ${ }^{1} \mathrm{H}$ NMR spectra

\begin{tabular}{|c|c|c|c|c|c|c|c|c|c|c|c|c|}
\hline \multirow{3}{*}{ 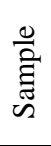 } & \multirow{3}{*}{$\begin{array}{c}w / w \\
\text { asph* }\end{array}$} & \multicolumn{11}{|c|}{ Spectral range / ppm } \\
\hline & & $\mathrm{K}$ & $\mathrm{J}$ & I & $\mathrm{H}$ & G & $\mathrm{F}$ & E & D & $\mathrm{C}$ & B & A \\
\hline & & $\begin{array}{c}0.5- \\
1.0\end{array}$ & $\begin{array}{l}1.0- \\
1.7\end{array}$ & $\begin{array}{l}1.7- \\
1.9\end{array}$ & $\begin{array}{l}1.9- \\
2.1\end{array}$ & $\begin{array}{c}2.1- \\
2.4\end{array}$ & $\begin{array}{c}2.4- \\
3.5\end{array}$ & $\begin{array}{c}3.5- \\
4.5\end{array}$ & $\begin{array}{l}6.0- \\
7.2\end{array}$ & $\begin{array}{l}7.2- \\
8.3\end{array}$ & $\begin{array}{c}8.3- \\
8.9\end{array}$ & $\begin{array}{c}8.9- \\
9.3\end{array}$ \\
\hline 1 & 0.74 & 0.99 & 1.78 & 4.35 & 2.77 & 2.17 & 6.53 & 2.37 & 1.38 & 2.77 & 55.14 & 19.76 \\
\hline 2 & 10.70 & 0 & 0.35 & 3.48 & 2.61 & 0.35 & 8.17 & 2.96 & 2.09 & 4 & 58.61 & 17.39 \\
\hline 3 & 5.26 & 0.18 & 0.55 & 3.31 & 1.65 & 0.92 & 7.72 & 2.76 & 2.21 & 4.04 & 58.27 & 18.38 \\
\hline 4 & 3.38 & 0.85 & 1.53 & 3.91 & 3.40 & 1.87 & 6.12 & 2.38 & 1.70 & 3.23 & 55.61 & 17.01 \\
\hline 5 & 12.50 & 0.18 & 0.54 & 3.57 & 2.32 & 1.41 & 10.34 & 3.20 & 2.32 & 3.92 & 54.37 & 17.83 \\
\hline 6 & 0.80 & 0.20 & 0.40 & 2.02 & 1.41 & 0.40 & 4.84 & 2.02 & 1.41 & 3.63 & 63.51 & 20.16 \\
\hline 7 & 12.80 & 0.19 & 0.19 & 2.83 & 1.89 & 0.19 & 7.92 & 2.83 & 1.70 & 3.77 & 59.62 & 18.87 \\
\hline 8 & 0.95 & 0.16 & 0.65 & 2.43 & 1.46 & 0.81 & 4.21 & 1.46 & 0.92 & 2.43 & 69.21 & 16.21 \\
\hline 9 & 1.60 & 0.20 & 0.40 & 2.40 & 1.60 & 0.06 & 6.40 & 2.40 & 1.80 & 3.80 & 60.40 & 20 \\
\hline 10 & 5.50 & 0 & 0.19 & 2.11 & 2.68 & 0.38 & 7.28 & 3.06 & 2.12 & 4.02 & 59.19 & 18.97 \\
\hline 11 & 1.82 & 0.17 & 0.69 & 2.78 & 1.74 & 1.04 & 6.26 & 2.26 & 1.39 & 2.78 & 63.48 & 17.39 \\
\hline 12 & 1.00 & 0.20 & 0.40 & 3.04 & 2.42 & 0.61 & 8.19 & 3.24 & 2.02 & 4.05 & 56.07 & 20.24 \\
\hline 13 & 0.79 & 0.19 & 0.19 & 1.93 & 1.93 & 0.39 & 5.22 & 2.03 & 1.74 & 3.67 & 63.25 & 19.34 \\
\hline 14 & 3.09 & 1.67 & 0.50 & 3.17 & 2.16 & 0.67 & 7.66 & 2.50 & 1.83 & 3.67 & 55.50 & 16.67 \\
\hline 15 & 3.70 & 0.93 & 1.70 & 4.64 & 3.25 & 2.17 & 8.51 & 2.63 & 1.86 & 3.25 & 55.57 & 15.48 \\
\hline 16 & 4.70 & 0.40 & 1.04 & 3.31 & 2.07 & 1.45 & 7.45 & 2.48 & 1.86 & 3.52 & 55.70 & 20.70 \\
\hline 17 & 1.80 & 0 & 0.19 & 1.90 & 2.09 & 0.19 & 4.95 & 2.48 & 1.71 & 3.24 & 64.19 & 19.05 \\
\hline 18 & 7.70 & 0.06 & 0.20 & 2.60 & 1.80 & 0.60 & 7.60 & 3 & 2 & 3.80 & 58.36 & 19.99 \\
\hline 19 & 8.80 & 0.17 & 0.69 & 3.60 & 2.25 & 1.56 & 9.70 & 2.94 & 1.91 & 3.99 & 55.803 & 17.33 \\
\hline 20 & 26.50 & 0.20 & 0.64 & 3.60 & 2.10 & 1.10 & 9 & 3.60 & 2.40 & 4.70 & 51.20 & 21.41 \\
\hline 21 & 0.10 & 0.27 & 0.08 & 1.93 & 1.65 & 0.08 & 5.22 & 2.75 & 1.65 & 3.58 & 55.28 & 27.50 \\
\hline 22 & 0.20 & 0.023 & 0.27 & 2.20 & 2.20 & 0.03 & 5.70 & 2.70 & 1.60 & 3.50 & 54.80 & 27 \\
\hline 23 & 0.08 & 0.094 & 0.24 & 1.89 & 1.60 & 0.236 & 5.42 & 2.36 & 1.40 & 3.29 & 59.85 & 23.56 \\
\hline 24 & 0.05 & 0 & 0 & 1.70 & 1.70 & 0 & 4.69 & 2.47 & 1.23 & 2.96 & 60.49 & 24.69 \\
\hline 25 & 0.10 & 0 & 0.23 & 2.31 & 1.85 & 0.23 & 4.85 & 2.08 & 1.16 & 3 & 61.20 & 23.09 \\
\hline 26 & 0.16 & 0.22 & 0.43 & 2.61 & 1.96 & 0.44 & 5.66 & 2.18 & 1.31 & 3.27 & 60.13 & 21.79 \\
\hline 27 & 0.10 & 0 & 0.22 & 1.94 & 1.94 & 0.22 & 4.97 & 2.16 & 1.08 & 2.37 & 63.50 & 21.60 \\
\hline 28 & 0.12 & 0 & 0.206 & 2.27 & 1.65 & 0.41 & 5.57 & 2.06 & 1.24 & 2.47 & 63.505 & 20.62 \\
\hline 29 & 0.08 & 0 & 0 & 2.18 & 1.96 & 0.218 & 6.75 & 2.40 & 1.10 & 2.61 & 61 & 21.78 \\
\hline 30 & 0.11 & 0.07 & 0.21 & 2.49 & 1.87 & 0.21 & 7.48 & 2.49 & 1.25 & 3.16 & 60.04 & 20.77 \\
\hline 31 & 0.09 & 0.21 & 0.43 & 1.93 & 1.29 & 4.29 & 4.50 & 1.71 & 1.07 & 2.58 & 64.37 & 21.46 \\
\hline 32 & 0.04 & 0.077 & 0.23 & 1.60 & 1.37 & 0.23 & 3.88 & 2.05 & 0.91 & 2.73 & 64.10 & 22.81 \\
\hline
\end{tabular}

* ASTM D 6560-12. 